Jurnal Kejuruteraan SI 1(4) 2018: 27-35

http://dx.doi.org/10.17576/jkukm-2018-si1(4)-04

\title{
Liquid-liquid Mixing in Y-type Microchannel
}

\author{
(Percampuran Sempurna Antara Cecair-cecair di dalam Saluran Mikro Jenis-Y) \\ Nur Tantiyani Ali Othman ${ }^{\mathrm{a}, \mathrm{b}^{*}}$, Ahmad Amri Anis ${ }^{\mathrm{b}}$ \\ ${ }^{a}$ Research Centre for Sustainable Process Technology (CESPRO) \\ ${ }^{b}$ Chemical Engineering Programme, \\ Faculty of Engineering and Built Environment, \\ Universiti Kebangsaan Malaysia, Selangor, Malaysia
}

ABSTRACT

\begin{abstract}
Mixing in a chemical industry is a crucial as the quality of a final product depends on the mixing process. Normally, mixing in a microchannel is based on their diffusivity without turbulence flow effect which causes of its laminar flow nature in the microchannel. However, the diffusivity in the microchannel is limited by its short passage. Thus, the objective of this study is to observe the behavior of liquid-liquid mixing (acetone-water) at different condition of feed velocity; 0.01-0.10 m/s, initial concentration by volume fraction; 0.1-0.6 w/w\% and design of Y-type microchannel; without and an existence of the obstacle. In this study, the Y-type microchannel is designed by SolidWorks ${ }^{\odot}$ software and these models then are imported and meshing into AnsysCF $X^{\circledR}$. This Y-type microchannel has two inlets and one outlet with the distance from the inlets to the $Y$ intersection point is $550 \mu \mathrm{m}$ and the length of a straight channel is $1200 \mu \mathrm{m}$. From this study, it shows a well-mixed flow pattern was observed as the velocity at the inlet $A$ is $v_{A}=0.10 \mathrm{~m} / \mathrm{s}$ and inlet $B$ is $v_{B}=0.05 \mathrm{~m} / \mathrm{s}$, with the average velocity is $v_{o}=0.075 \mathrm{~m} / \mathrm{s}$ which gives the best mixing condition. Other than that, due to a severe difference on the initial concentration fed at both inlets, create the mixing process requires a longer time or lengthier channel to achieve an equilibrium mixing point due to slow molecular diffusion. Besides, the mixing behavior in the Y-type microchannel with the obstacle shows better mixing's efficiency performance as the presence of obstacle need an extra interaction and momentum to enhances the liquid-liquid mixing.
\end{abstract}

Keywords: Mixing; Microchannel; AnsysCFX ${ }^{\odot} ; C F D^{\circledR}$; Liquid-liquid interaction

\section{INTRODUCTION}

Mixing is a basic process of two or more different component becomes a mixture component. In the chemical industry, it is very crucial processes since it will determine the quality of a final product. The objective of mixing is to decrease inequalities and uneven of solute composition in a mixture of two components and to change the fluid flow from heterogeneous to more homogenous condition. By that way, the fluid in the flow becomes less non-uniform by dilute the concentration, density, temperature and others (Almeida et al. 2016). As well, the mixing behavior is studied to understand of flow structure of process and mixing mechanism (Rudyak et al. 2014) in the system. Generally, mixing in the multiphase flow can be classified into different mixing phase such as solid-liquid, liquid-liquid, gas-liquid and etc. (Johnson et al. 2002 \& Ait Mouheb et al. 2012).

The fluid flow in a channel can be categorized into two classes; microchannel and macrochannel based on the range of its hydraulic diameter. The microchannel is commonly applied in a bioprocess application with laminar flow. The microchannel is defined as the channel with the hydraulic diameter range of 1-200 $\mu \mathrm{m}$ (Othman et al. 2012). Normally, mixing in the microchannel is based on their diffusivity without turbulence flow effect cause of their laminar flow nature in the microchannel. But, the diffusivity in the microchannel is limited by its short passage. Thus, it is conducted by branch the mainstream of fluid to many substreams to increase the area surface contact between two components to diffuse with each other (Henrik et al. 2000).

The mixing flow can be categorized into four classes; bulk transport, turbulent, laminar mixing or molecular diffusion (Engler et al. 2004 \& Bothe et al. 2006). Yet, in the microchannel, only laminar mixing and molecular diffusion can be applied due to the microchannel nature design. The laminar mixing has occurred when two liquids is contacted by side of their contact surface area while molecular diffusion acted as the main mechanism where the molecule is transported from dense to the dilute concentration. Besides, the molecular diffusion is influenced by the diffusion coefficient which based on its viscosity factor and molecule size. As a result, the volume concentration distribution at the initial boundary will keep decreasing as the mixing occurred.

The previous study on the mixing behavior in the microchannel has been carried out by laboratory experiment which requires the built of a prototype. These laboratory experiments have shown the real data with the fundamental hypothesis, meanwhile the simulation technique only depends on the hypothesis that was generated from its programmed. Although the simulation technique showed some an advantages over the real hands-on experiment, the simulation technique has the accurate calculation and 
capability to choose a model type and inlet data for each study (Eswaran et al. 1988, Iglberger et al. 2008, Jason 2010 \& Othman et al. 2017). Yet, the laboratory experiment has shown a few constraints such as time-limited, bulky equipment and more expenses is needed. Due to that, numerous studies have been done in order to determine the factors that influence the liquids mixing in the microchannel to achieve well mixing (Soleymani et al. 2008, Ait Mouheb et al. 2012, Milozic et al. 2014 \& Othman et al. 2018). In addition, there is two type of micro-mixing either by active or passive micromixer. The active micromixer requires an external force in order to enhance its mixing process; however, the active micromixer has some constraints with its complex fabrication and need some external installation cost. Therefore, due to these constraints, the passive micromixer is more preferred.

As well, the geometry factor such as an obstacle in the microchannel also has been studied which is considered as the alternative to increase the mixing efficiency on the passive micromixer (Wang et al. 2002). Normally, for mixing purpose, the Y-, T- and serpentine-shape type microchannel is commonly used in the numerous previous studies such as by Soleymani et al. 2008, Othman et al. 2012, Ait Mouheb et al. 2012, Othman et al. 2013, Milozic et al. 2014, Othman et al. 2015 \& Othman et al. 2018. Different type of the microchannel is designed with channel geometry that will increase the surface area contact for liquids which gives the higher molecular diffusion for well-mixing condition. The liquid mixing with T-shape type microchannels were carried out to highlighted the three laminar flow regimes in the mixing channel namely, stratified flow, vortex flow and engulfment flow (Engler et al. 2004, Bothe et al. 2006, Soleymani et al. 2008 and Ait Mouheb et al. 2012). As well, it shown the Y-shape type microchannel is the simplest model with two inlets and one outlet since the mixing time can be shortening by using higher flow rate in the passive microchannel (Wong et al. 2004 \& Othman et al. 2015).

Besides, adding of the cylinder obstacle in the microchannel helps to disrupt the liquid flow and reduce the membrane layer width on the liquid, as well enhances the mixing time in the microchannel (Wang et al. 2002). Hence, in this study, the liquid-liquid mixing (acetone-water) and flow pattern in the Y-type microchannel was observed at different condition of the feed velocity; $0.01-0.10 \mathrm{~m} / \mathrm{s}$, initial concentration; $0.1-0.6 \mathrm{w} / \mathrm{w} \%$ by volume fraction and two designs of the Y-type microchannel; without and the existence of obstacle in the microchannel.

\section{METHODOLOGY}

In this study, Y-type microchannel with and without cylinder obstacle is designed to observe the liquids behavior and flow pattern in the microchannel. The aluminum is used as the built material, while acetone and water are used as the feed of inlets $\mathrm{A}$ and $\mathrm{B}$ with a composition of acetone and water mixture. Two parameters; feed velocity between $0.01-0.10$ $\mathrm{m} / \mathrm{s}$ and inlets feed composition between of 0.1-0.6 w/w\% of acetone is fed to the inlets to observe the mixing pattern in the microchannel. This simulation was conducted using SolidWorks ${ }^{\circledR}$ and AnsysCFX ${ }^{\circledR}$ software academic version 17.2. There are five steps in this simulation process where the details process is shown as in Figure 1.

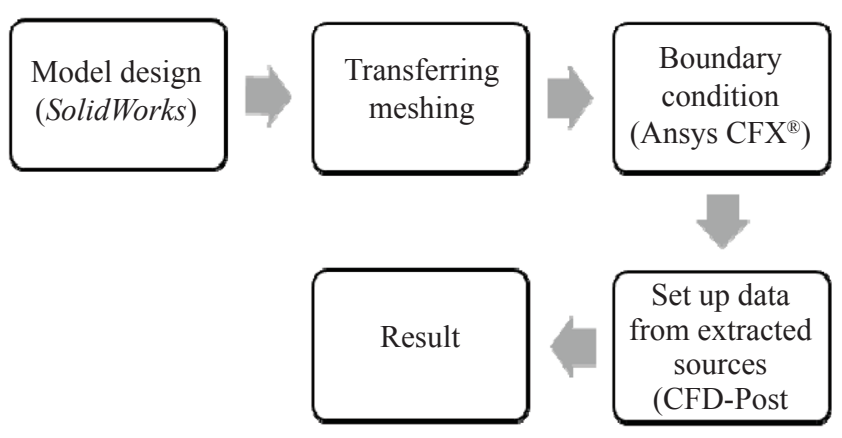

FIGURE 1. A step of the simulation process Y-Type Microchannel Design

Y-TYPE MICROCHANNEL DESIGN

Firstly, the Y-type microchannel is designed by SolidWorks ${ }^{\odot}$ and then the model is imported and meshing into the AnsysCFX $^{\circledR}$ software for further simulation step including define the boundary condition and set up the parameter. In this study, there are two designs of the Y-type microchannel; without cylinder obstacle and another one has a cylinder obstacle inside the channel. Both of these design models have the same dimension, only the presence of the cylinder obstacle makes these two model difference. Figure 2 shows the design of Y-type microchannel with (a) its details dimension and cross-section view (b) without and (c) with cylinder obstacle.

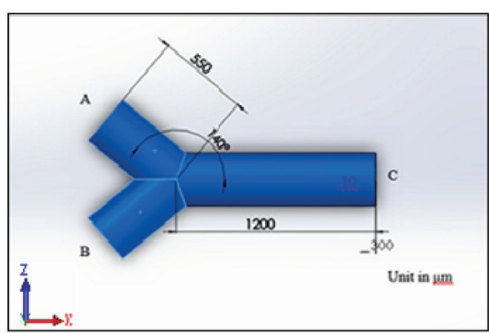

(a)

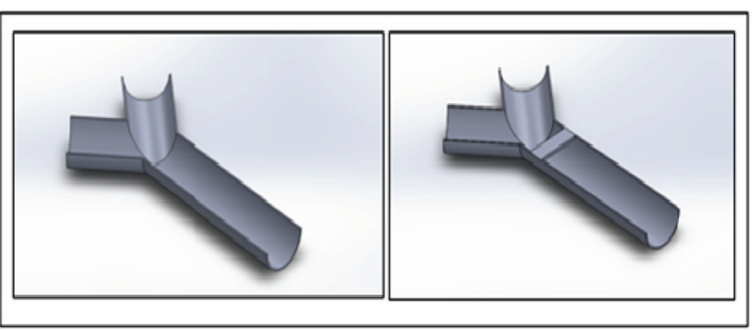

(b) (c)

FIGURE 2. Y-type microchannel design with (a) details dimension, (b) cross-section view of Y-type microchannel without cylinder obstacle and (c) cross-section view of Y-type microchannel with cylinder obstacle 
The microchannel consists of two inlets and one outlet with the hydraulic diameter size is $300 \mu \mathrm{m}$. The length of the straight channel is $1200 \mu \mathrm{m}$ with the angle between inlets and $\mathrm{Y}$ intersection is $140^{\circ}$. The distance between the inlets to the $\mathrm{Y}$ intersection is $550 \mu \mathrm{m}$ and the diameter size of cylinder obstacle is $100 \mu \mathrm{m}$. The location of the obstacle is $150 \mu \mathrm{m}$ from the intersection point of both inlets A and B. Then, transferring meshing is conducted to set a mode of a simulation model. For this simulation, structured and composed of solid grids is set up for both of Y-type microchannel design. The grid solid structured type of meshing is set up for this three dimensional (3D) microchannel model. The pinch tolerance used for this meshing is $8.95 \times 10^{-7} \mathrm{~m}$.

\section{SET UP OF BOUNDARY CONDITION AND PARAMETERS}

There are three boundary conditions are defined in this microchannel design; inlets $\mathrm{A}$, inlet $\mathrm{B}$ and outlets $\mathrm{C}$. The liquid solution of acetone and water are mixed with the variation of acetone and water composition are used as the feed of inlets A and B. The details properties of the water and acetone are shown in Table 1 . The molecular diffusivity of acetone and water is $4.56 \times 10^{-5} \mathrm{~cm}^{2} / \mathrm{s}$. The pressure is set up at $1 \mathrm{~atm}$ with room temperature at $25^{\circ} \mathrm{C}$. The heat transfer is negligible since no changes of temperature observed within the microchannel system.

TABLE 1. Properties of water and acetone

\begin{tabular}{lcc}
\hline Property & Water & Acetone \\
\hline Density $\left(\mathrm{kg} / \mathrm{m}^{3}\right)$ & 997 & 780 \\
Specific heat capacity $(\mathrm{kJ} / \mathrm{kg} \mathrm{K})$ & 4.18 & 2.15 \\
Boiling point $\left({ }^{\circ} \mathrm{C}\right)$ & 100 & 56 \\
Viscosity $(\mathrm{cP})$ & 1.002 & 0.320 \\
\hline
\end{tabular}

Source: Ansys ${ }^{\circ}$ database

There are two parameters; feed velocity and an initial concentration at both inlets $\mathrm{A}$ and $\mathrm{B}$ that are manipulated in order to observe and to achieve the optimum mixing condition. The details range of each parameter is shown as in Table 2 and Table 3. The feed velocity is adjusted at the range of $0.01-0.10 \mathrm{~m} / \mathrm{s}$ based on the previous study (Othman et al. 2015) where the Reynolds number behaves under the laminar flow in the microchannel should be 1 to 100 . While the initial concentration of acetone-water mixed is varied at the inlets $\mathrm{A}$ and $\mathrm{B}$ at the range of $0.1-0.6$ by the volume fraction in order to observe the mixing and flow pattern in the microchannel.

TABLE 2. The velocity of inlet $A$ and inlet $B, v_{A}$ and ${ }_{v B}$

\begin{tabular}{ccc}
\hline No of Simulation & $\mathrm{v}_{\mathrm{A}}(\mathrm{m} / \mathrm{s})$ & $\mathrm{v}_{\mathrm{B}}(\mathrm{m} / \mathrm{s})$ \\
\hline 1.1 & 0.05 & 0.05 \\
1.2 & 0.10 & 0.05 \\
1.3 & 0.10 & 0.03 \\
1.4 & 0.10 & 0.01 \\
\hline
\end{tabular}

TABLE 3. The volume fraction of acetone at the inlet $\mathrm{A}$ and inlet $\mathrm{B}, \psi_{\mathrm{A}}$ and $\psi_{\mathrm{B}}$

\begin{tabular}{ccc}
\hline No of Simulation & $\psi_{\mathrm{A}}$ & $\psi_{\mathrm{B}}$ \\
\hline 2.1 & 0.6 & 0.6 \\
2.2 & 0.6 & 0.3 \\
2.3 & 0.3 & 0.2 \\
2.4 & 0.1 & 0.6 \\
\hline
\end{tabular}

\section{RESULT AND DISCUSSION}

To study and determine the mixing behavior of the acetonewater in the Y-type microchannel, the flow pattern of liquid-liquid density and volume fraction distribution are observed with the variation on the feed velocity, $v$ and initial concentration of acetone, $\psi$ feeds through the microchannel. In this study, the mixing behavior in the microchannel is visualized based on a variation of the feed velocity and initial concentration of acetone, as well the design of Y-type microchannel model either with or without the cylinder obstacle.

\section{VELOCITY EFFECT ON THE FLOW PATTERN OF VOLUME FRACTION DISTRIBUTION IN Y-TYPE MICROCHANNEL WITHOUT OBSTACLE}

In this simulation, firstly, the effect of the feed velocity on the flow pattern of the volume fraction distribution in the Y-type microchannel without obstacle was observed. Four simulation tests are done with the velocity's variation at the inlets $\mathrm{A}$ and $\mathrm{B}, v_{A}$ and $v_{B}$. The volume fraction of acetone at the inlets $\mathrm{A}$ and $\mathrm{B}$ are fixed at $\psi=0.5$. Figure 3 shows the flow pattern of the volume fraction distribution in the microchannel without obstacle at different feed velocity at the inlets A and B. Only simulation 1.1 (Figure 3(a)) used the similar velocity for both inlets A and B (refer Table 2 for details), while the other simulation used different velocity for inlet $\mathrm{A}$ and $\mathrm{B}$. For simulation 1.1; both of inlets $\mathrm{A}$ and $\mathrm{B}$ is set up at $v=0.05 \mathrm{~m} / \mathrm{s}$, in simulation 1.2; inlet $\mathrm{A}$, $v_{A}=0.1 \mathrm{~m} / \mathrm{s}$ and inlet $\mathrm{B}, v_{B}=0.05 \mathrm{~m} / \mathrm{s}$, in simulation 1.3 ; inlet A, $v_{A}=0.1 \mathrm{~m} / \mathrm{s}$ and inlet $\mathrm{B}, v_{B}=0.03 \mathrm{~m} / \mathrm{s}$ and in simulation 1.4 ; inlet $\mathrm{A}, v_{A}=0.1 \mathrm{~m} / \mathrm{s}$ and inlet $\mathrm{B}, v_{B}=0.01 \mathrm{~m} / \mathrm{s}$. The result shows the fluid volume fraction where the color bar at the left side represents the volume fraction of the acetone-water mixture in the microchannel. The dark blue color shows the lowest volume fraction distribution (0-0.1), while red color shows the highest volume fraction distribution (0.9-1.0) was observed along the flow microchannel.

As the overall, these simulation results show that the highest volume fraction distribution was observed at the center area of microchannel which indicated with the green color, while the lowest volume fraction distribution is observed at near the channel wall which indicated with the dark blue color. This is occurred due to the nature of laminar flow profile in a microchannel where the minimum velocity is observed at near to the channel wall. Besides, the wall's velocity is almost zero due to the shear stress effect and interaction between the wall surfaces at near the channel wall. 


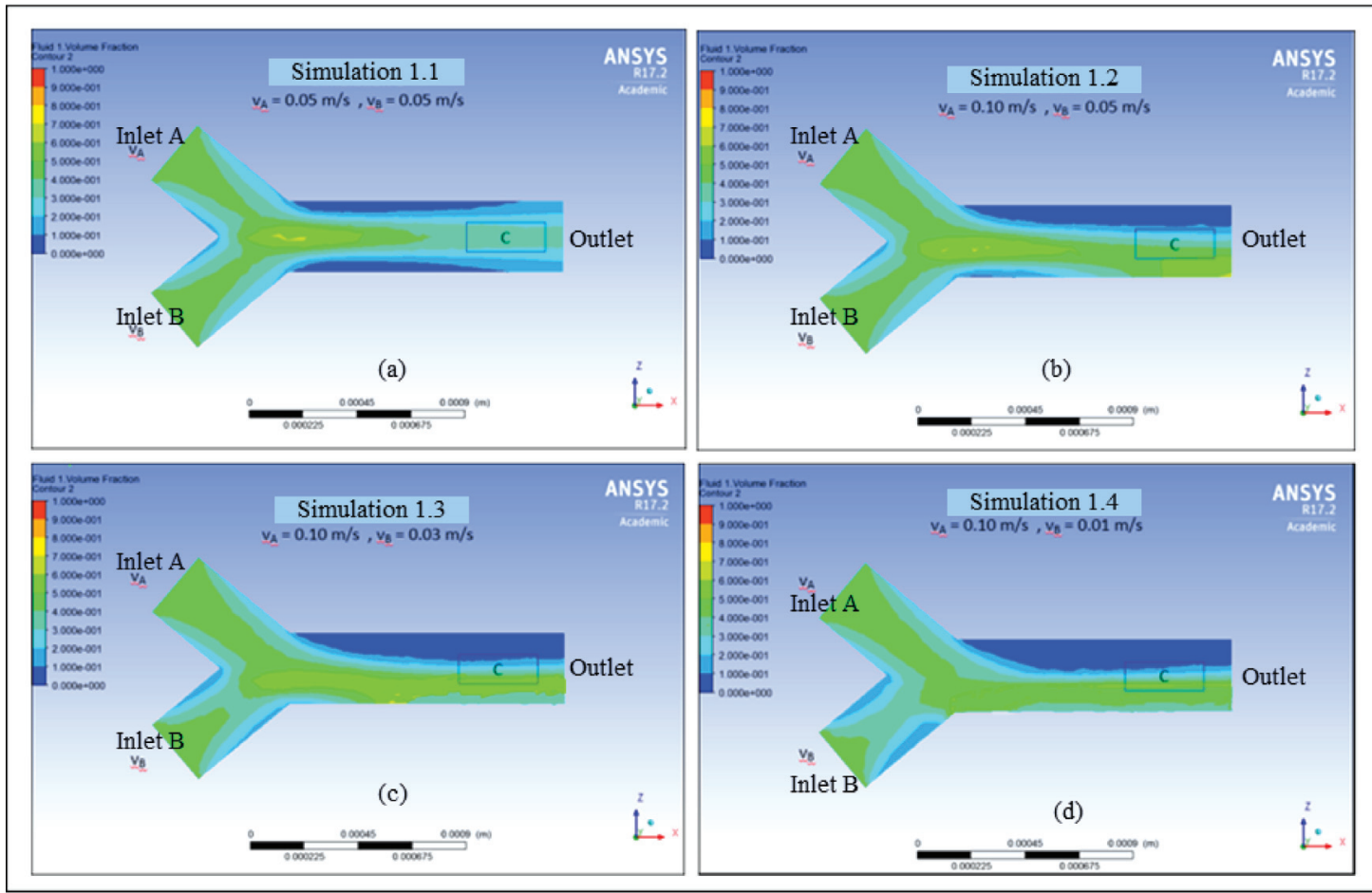

FIGURE 3. Comparison of four simulation conditions with the variation of inlets A and B velocity on the flow pattern of volume fraction distribution in the microchannel without obstacle with velocity at (a) both of inlets A and B is $v=0.05$ $\mathrm{m} / \mathrm{s}$, (b) $v_{A}=0.1$ and $v_{B}=0.05 \mathrm{~m} / \mathrm{s}$, (c) $v_{A}=0.1$ and $v_{B}=0.03 \mathrm{~m} / \mathrm{s}$ and (d) $v_{A}=0.1$ and $v_{B}=0.01 \mathrm{~m} / \mathrm{s}$

Moreover, based on the flow pattern of the volume fraction distribution in the four simulations, it was observed that as the similar velocity is applied at both of the inlets A and $\mathrm{B}$, the mixing point of two inlets channel is occurred and focused at the center area of the microchannel. On the other hands, when the different velocity is applied at the inlet $\mathrm{A}$ and $\mathrm{B}$, the mixing point from two inlets are seemed to be moved toward the lower side of the feed velocity's source. For example, in the simulation 1.1 , as the velocity at both inlets is $v=0.05 \mathrm{~m} / \mathrm{s}$, the highest mixing point was observed at the intersection of two inlets area and focused on the center area. On the other side, in the others simulation; $1.2,1.3$ and 1.4 , the mixing point was not focused on the center area, but towards the side of a channel which the lower feed velocity was applied. It can be observed that the mixing process is occurred at underneath of the center line as the velocity at the inlet $\mathrm{B}$ is lower compare to the velocity at the inlet A. Due to this phenomenon, the volume fraction of the acetonewater mixture is well-distributed as the liquid flow continue undergoes the molecular diffusion until passing through the outlet area.

In addition, as shown in Figure 3, in this study, region $\mathrm{C}$ is defined as the stable mixing area in the microchannel. For better understanding, Table 4 summarized the volume fraction distribution of the acetone-water mixture at the region $\mathrm{C}$ with the variation of inlets velocity. It shows the simulation 1.2 and 1.3 with the highest average inlet velocity at $v=0.075 \mathrm{~m} / \mathrm{s}$ and $v=0.065 \mathrm{~m} / \mathrm{s}$, shown the well-mixed volume fraction distribution occurred at the region $\mathrm{C}, \psi_{\mathrm{C}}$ which represents about $0.5-0.6$ volume fraction of acetonewater mixture compare to the others simulation condition. These results show the operation condition in the simulation 1.2 and 1.3 is able to achieve more homogenous mixing compared to the simulation 1.1 and 1.4. But, the condition in the simulation 1.2 shown better mixing flow pattern as compared to the simulation 1.3 due to the smallest area of blue color; the lowest volume fraction distribution. From this overall simulation, a high average inlet velocity provides the best mixing distribution along the Y-type microchannel since the mixing behavior in the microchannel is solely occurred due to the molecular diffusion between the acetone and water; as well influenced by the average inlet velocity.

TABLE 4. Summarized the volume fraction distribution of acetonewater mixture at the region $\mathrm{C}$

\begin{tabular}{ccc}
\hline Simulation & $\begin{array}{c}\text { Average inlet velocity, } \\
v_{\mathrm{o}}(\mathrm{m} / \mathrm{s})\end{array}$ & $\begin{array}{c}\text { Acetone volume } \\
\text { fraction at region } \mathrm{C}, \psi_{\mathrm{c}}\end{array}$ \\
\hline 1.1 & 0.050 & 0.40 \\
1.2 & 0.075 & 0.58 \\
1.3 & 0.065 & 0.52 \\
1.4 & 0.055 & 0.45 \\
\hline
\end{tabular}

VELOCITY EFFECT ON THE FLOW PATTERN OF DENSITY DISTRIBUTION IN Y-TYPE MICROCHANNEL WITHOUT OBSTACLE

As well, the velocity effect on the flow pattern of density distribution in the Y-type microchannel without obstacle was observed. Four simulation tests are studied with velocity 
variation at the inlets $\mathrm{A}$ and $\mathrm{B}$. The volume fraction of the acetone-water mixture at both inlets $\mathrm{A}$ and $\mathrm{B}$ are fixed at $\psi=$ 0.5 . Figure 4 shows the flow pattern of density distribution in the microchannel without cylinder obstacle with the velocity variation at the inlets $\mathrm{A}$ and $\mathrm{B}$. Only simulation 1.1 (Figure 4(a)) used the similar velocity for both inlets, while the other simulation used the different velocity at the inlet A and B. The color bar represents the density distribution of the acetonewater mixture in the microchannel where the dark blue color shows the lowest density distribution with the value of 778 $\mathrm{kg} / \mathrm{m}^{3}$ (acetone only). While the red color shows the highest density distribution with value of $998 \mathrm{~kg} / \mathrm{m}^{3}$ (water only) was observed along the microchannel.

As the overall, these simulations result shows the same result with the volume fraction distribution where the well-mixed density was observed at the center area of microchannel which indicated with the green color. While the highest density at near the channel wall which indicated with the red color. The red color on the channel wall side shows that region has a composition of water volume fraction at value 1.0 with density distribution was observed as 998 $\mathrm{kg} / \mathrm{m}^{3}$. Meanwhile, the dark blue color represents on that region has the maximum composition of the acetone volume fraction; 1.0 and the green color shows the composition of the acetone volume fraction at $0.5 \%$ with the density distribution is $898 \mathrm{~kg} / \mathrm{m}^{3}$. It shows the higher velocity interrupt the flow for being and achieve the well-mixed flow condition as compare to the lowest feed velocity. Besides, at the region $\mathrm{C}$, the highest density distribution was observed in the simulation 1.1 and simulation 1.4 as the value of 938 $\mathrm{kg} / \mathrm{m}^{3}$ was showed which represents in the green lime color compared to the simulation 1.2 and simulation 1.3. This density distribution shows the changes properties of liquids mixing was occurred in the microchannel. The properties of liquid become more homogenous after mixing occurs by molecular diffusion between two solutions from both inlets. The liquid molecular diffused as the surface of liquids is in the contact between them.

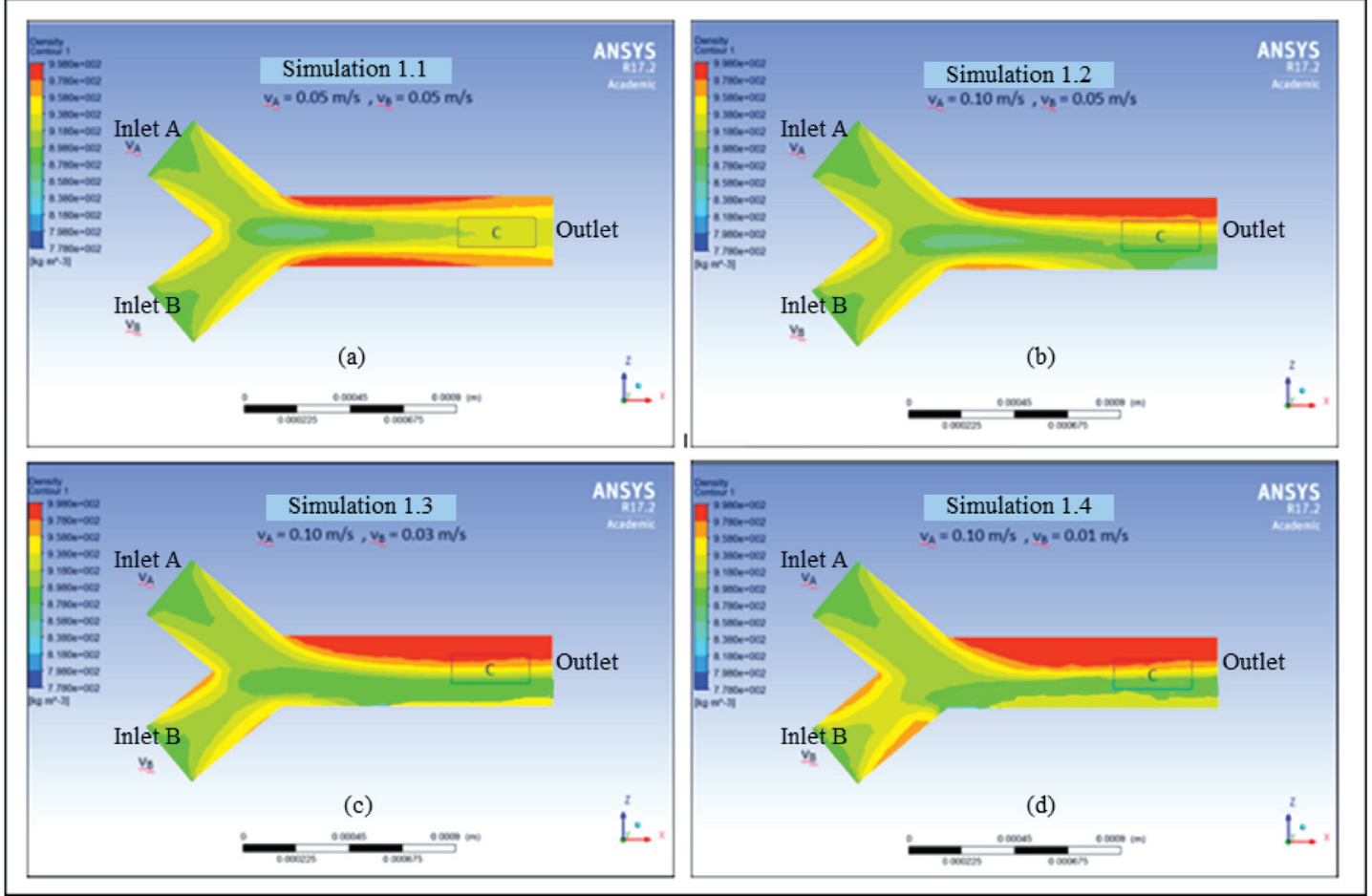

FIGURE 4. Comparison of four simulation conditions with the variation of inlets A and B velocity on the flow pattern of density distribution in the microchannel without obstacle with velocity at (a) both of inlets A and B is $v=0.05 \mathrm{~m} / \mathrm{s},(\mathrm{b}) v_{A}=0.1$ and $v_{B}=0.05 \mathrm{~m} / \mathrm{s}$, (c) $v_{A}=0.1$ and $v_{B}=0.03 \mathrm{~m} / \mathrm{s}$ and (d) $v_{A}=0.1$ and $v_{B}=0.01 \mathrm{~m} / \mathrm{s}$

INITIAL CONCENTRATION EFFECT ON THE FLOW PATTERN OF VOLUME FRACTION DISTRIBUTION IN Y-TYPE MICROCHANNEL WITHOUT OBSTACLE

Furthermore, the effect of the initial liquid concentration $(0.1-0.6 \mathrm{w} / \mathrm{w} \%)$ on the flow pattern of the volume fraction distribution in the Y-type microchannel without obstacle was observed. Four simulation tests are studied with the variation of the initial concentration of acetone-water mixture that fed through the inlets $\mathrm{A}$ and $\mathrm{B}, \psi_{\mathrm{A}}$ and $\psi_{\mathrm{B}}$. The fluid velocity flow through the microchannel at both inlets is fixed at $v=$ $0.5 \mathrm{~m} / \mathrm{s}$.

Figure 5 shows the flow pattern of the volume fraction distribution in the microchannel without the obstacle with a variation of the initial concentration at the inlets $\mathrm{A}$ and $\mathrm{B}$. Only the simulation 2.1 (Figure 5(a)) used the similar initial concentration of the acetone-water mixture at both inlets, while the other simulation used different initial concentration of acetone-water mixture for inlet $\mathrm{A}$ and $\mathrm{B}$. For simulation 2.1 ; both inlets $\mathrm{A}$ and $\mathrm{B}$ is fed with $\psi=0.6$, simulation 
2.2; inlet $\mathrm{A}, \psi_{\mathrm{A}}=0.6$ and inlet $\mathrm{B} \psi_{\mathrm{B}}=0.3$, simulation 2.3; inlet $\mathrm{A}, \psi_{\mathrm{A}}=0.3$ and inlet $\mathrm{B} \psi_{\mathrm{B}}=0.2$ and simulation 2.4; inlet $\mathrm{A}, \psi_{\mathrm{A}}=0.1$ and inlet $\mathrm{B} \psi_{\mathrm{B}}=0.6 \mathrm{w} / \mathrm{w} \%$. The color bar represents the volume fraction of the acetone-water mixture in the microchannel where dark blue color shows the lowest volume fraction (0-0.1), while the red color shows the highest volume fraction distribution (0.9-1.0) was observed along the microchannel flow.

For simulation 2.1 as shown in the Figure 5(a), as similar initial concentration was fed at both inlets $\mathrm{A}$ and $\mathrm{B} ; 0.6 \mathrm{w} / \mathrm{w} \%$, the uniform concentration distribution was observed at the center microchannel due to the effect shear stress and wall force. It is known that the parabolic velocity profile produces of zero velocity at near the channel wall. While due to high velocity at the center channel; the fluid was being transported and flow moved toward the center of the microchannel (Othman et al. 2013, Othman et al. 2017). In the simulation 2 and 4, as the initial concentration of the acetone-water mixture that fed through the one inlet is denser compared to the others side inlet, more volume fraction distribution was observed toward the opposite side of the channel wall of the dense concentration's feed due to the effect of velocity and shear stress effect at the near to channel wall.

Table 5 summarized the final volume fraction distribution of acetone-water mixture at the region $\mathrm{C}$ with the variation of initial concentration that fed through the inlet $\mathrm{A}$ and $\mathrm{B}$, $\psi_{\mathrm{A}}$ and $\psi_{\mathrm{B}}$. It shows that the simulation 2.1 with the initial concentration at both inlets A and B is $\psi=0.6$ was achieved the well-mixed of acetone-water mixture which produced solution's concentration of $0.5 \mathrm{w} / \mathrm{w} \%$ at the region $\mathrm{C}$. Meanwhile, as the simulation 2.4 with the highest difference of the initial concentration, results the least mixing occurred since the final concentration at the region $\mathrm{C}$ was not achieve in a stable condition towards the end of a microchannel area. It is because the mixing due to the molecular diffusion in the microchannel is relatively slow especially when two solutions with a severe difference of concentration was mixed; longer time is required for the solutions to achieve the equilibrium level.

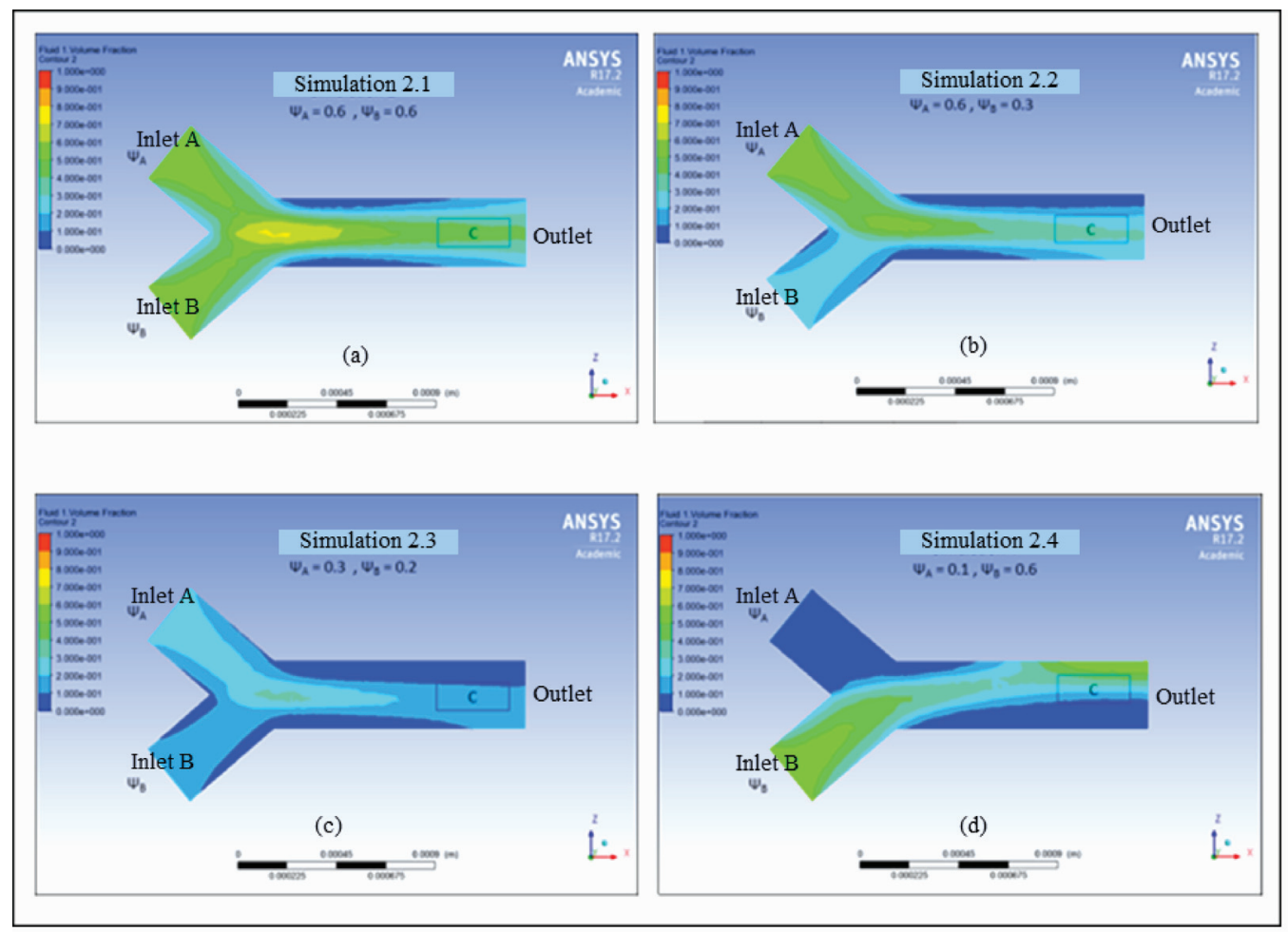

FIGURE 5. Comparison of four simulation conditions with the variation of initial concentration fed through inlets $\mathrm{A}$ and $\mathrm{B}$ on the flow pattern of volume fraction distribution in the microchannel without obstacle with initial concentration fed at (a) both inlets is $\psi=0.6$, (b) $\psi_{\mathrm{A}}=0.6$ and $\psi_{\mathrm{B}}=0.3$, (c) $\psi_{\mathrm{A}}=0.3$ and $\psi_{\mathrm{B}}=0.2$ and (d) $\psi_{\mathrm{A}}=0.1$ and $\psi_{\mathrm{B}}=0.6 \mathrm{w} / \mathrm{w} \%$

TABLE 5. Summarized of final concentration distribution of acetone-water mixture at the region C

\begin{tabular}{ccccc}
\hline Simulation & $\begin{array}{c}\text { Inlet A initial concentration, } \\
\psi_{\mathrm{A}}(\mathrm{w} / \mathrm{w} \%)\end{array}$ & $\begin{array}{c}\text { Inlet B initial concentration, } \\
\psi_{\mathrm{B}}(\mathrm{w} / \mathrm{w} \%)\end{array}$ & $\begin{array}{c}\text { Difference of initial concentration, } \\
\left|\psi_{\mathrm{A}}-\psi_{\mathrm{B}}\right|(\mathrm{w} / \mathrm{w} \%)\end{array}$ & $\begin{array}{c}\text { Final concentration at } \\
\text { region } \mathrm{C}, \psi_{\mathrm{C}}(\mathrm{w} / \mathrm{w} \%)\end{array}$ \\
\hline 2.1 & 0.6 & 0.6 & 0.0 & 0.50 \\
2.2 & 0.6 & 0.3 & 0.3 & 0.40 \\
2.3 & 0.3 & 0.2 & 0.1 & 0.25 \\
2.4 & 0.1 & 0.6 & 0.5 & 0.35 \\
\hline
\end{tabular}


TABLE 6. Summary comparison of mixing pattern on Y-type microchannel without the obstacle and Y-type microchannel with the obstacle

\begin{tabular}{|c|c|c|c|c|c|}
\hline \multirow[b]{2}{*}{ Simulation } & \multirow[b]{2}{*}{$\psi_{\mathrm{A}}(\mathrm{w} / \mathrm{w} \%)$} & \multirow[b]{2}{*}{$\Psi_{\mathrm{B}}(\mathrm{w} / \mathrm{w} \%)$} & \multirow{2}{*}{$\begin{array}{l}\text { A difference in initial concentration } \\
\text { from inlet } \mathrm{A} \text { and inlet from inlet } \\
\mathrm{A} \text { and inlet } \mathrm{B}\left|\psi_{\mathrm{A}}-\psi_{\mathrm{B}}\right|(\mathrm{w} / \mathrm{w} \%)\end{array}$} & \multicolumn{2}{|c|}{$\psi_{\mathrm{C}}(\mathrm{w} / \mathrm{w} \%)$} \\
\hline & & & & $\begin{array}{l}\text { Y-type microchannel } \\
\text { without obstacle }\end{array}$ & $\begin{array}{l}\text { Y-type microchannel } \\
\text { with obstacle }\end{array}$ \\
\hline 2.1 & 0.6 & 0.6 & 0.0 & 0.5 & 0.6 \\
\hline 2.2 & 0.6 & 0.3 & 0.3 & 0.4 & 0.5 \\
\hline 2.3 & 0.3 & 0.2 & 0.1 & 0.2 & 0.3 \\
\hline 2.4 & 0.1 & 0.6 & 0.5 & 0.3 & 0.4 \\
\hline
\end{tabular}

FLOW PATTERN OF VOLUME FRACTION DISTRIBUTION IN Y-TYPE MICROCHANNEL WITHOUT OBSTACLE AND WITH OBSTACLE

To observe the effect of microchannel geometry design in order to achieve well-mixing behavior, two design microchannels; Y-type microchannel without the obstacle and with the obstacle was designed. In this simulation, the volume fraction of the acetone at both inlets are set as a manipulated parameter with fixed velocity at $v=0.05 \mathrm{~m} / \mathrm{s}$. The range of the initial concentration of acetone-water mixture fed through the inlets $\mathrm{A}$ and $\mathrm{B}$ is between $0.1-0.6 \mathrm{w} / \mathrm{w} \%$. Figure 6 shows the effect of the initial concentration on the flow pattern of volume fraction distribution in two type microchannel; without cylinder obstacle design (left side of Figure 6) and with the cylinder obstacle design (right side of Figure 6).

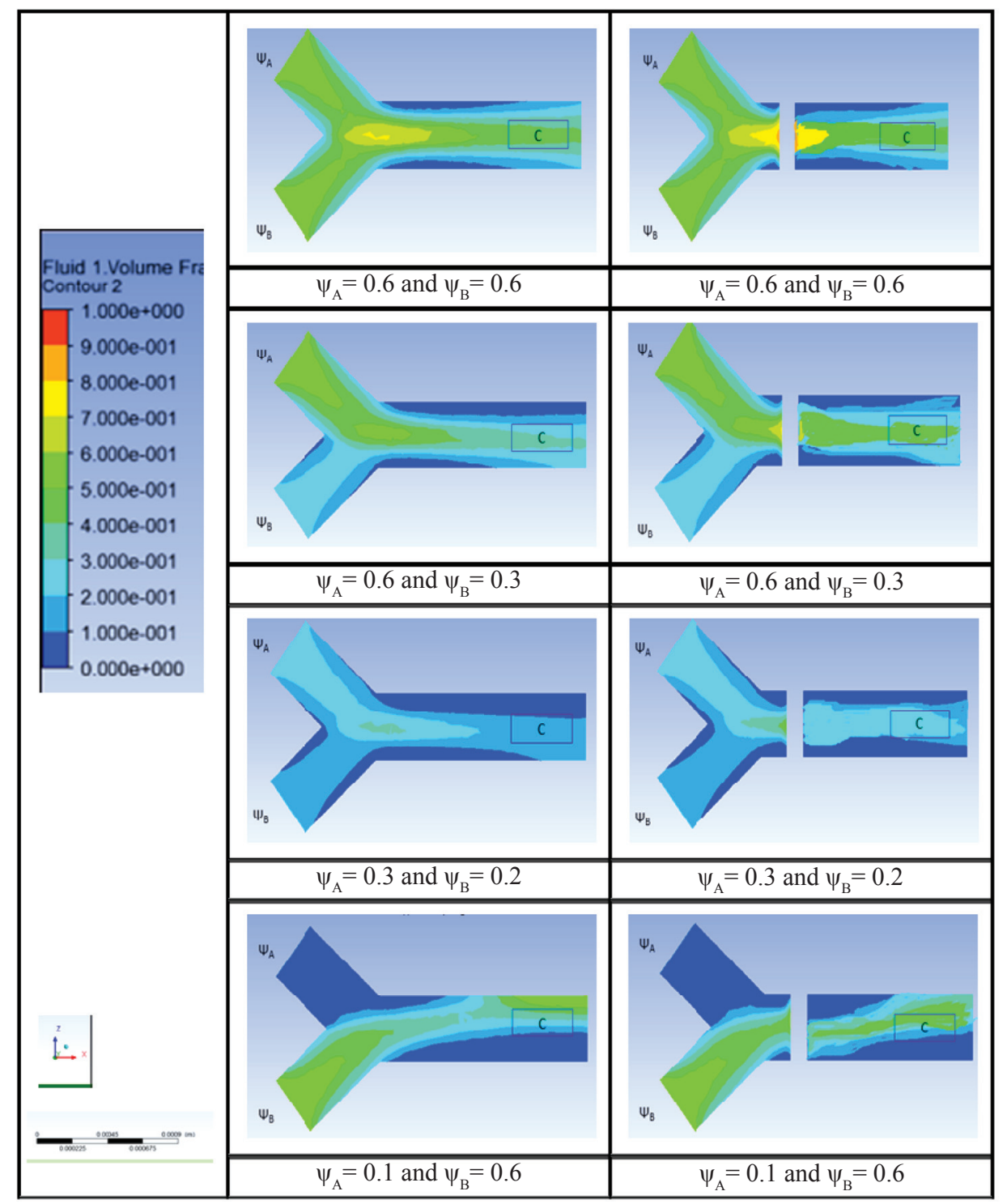

FIGURE 6. Comparison of four simulation conditions with the variation of initial concentration fed through inlets A and B on the flow pattern of volume fraction distribution in the microchannel without obstacle (left side column and with cylinder obstacle (right side column) 
For better understanding, Table 6 shows the summary of the volume fraction distribution at the two design types of the microchannel. It shows the design of the Y-type microchannel with obstacle gives a better mixing pattern compared to the Y-type microchannel without the cylinder obstacle. The existence of cylinder obstacle is functioned as the supportive geometry which contributes to achieving an efficiency of mixing. As the liquid pass through the obstacle, the liquid flow will have extra addition momentum which will cause the increasing of liquid-liquid mixing and residence time of molecular diffusion is increased in the microchannel. As the feed of two inlets have the drastic difference in the initial concentration as shown in the simulation 2.4 which the initial concentration at inlet $\mathrm{A}$ is $\psi_{\mathrm{A}}=0.1$ and at inlet $\mathrm{B}$ is $\psi_{\mathrm{B}}=0.6$. It shows that its requires either much longer time and lengthier channel to achieve the equilibrium point between this two feeds. On the other hand, with the presence of the cylinder obstacle in the Y-type microchannel, for example in the case of simulation 2.4, it enhances the mixing performance without the longer channel. Therefore, the supportive geometry such as cylinder obstacle helps to enhance the liquid-liquid mixing in the Y-type microchannel.

\section{CONCLUSION}

Two geometries design of the Y-type microchannel; without and with the cylinder obstacle are designed in this study in order to observe the effect of the initial concentration and feed velocity on the flow pattern of volume fraction and density distribution in the microchannel. The simulation results show at the average velocity of $v_{0}=0.075 \mathrm{~m} / \mathrm{s}$ and the initial concentration at the inlets $\mathrm{A}$ and $\mathrm{B}$ is $\psi=0.6$, it gives the best mixing condition based on the homogenous final concentration at the region $\mathrm{C}$. Besides, as the feed concentration is similar or likely same, then shorter time is requiring for molecular diffusion achieves equilibrium in liquids mixing. Lastly, it shows the final concentration at the region $\mathrm{C}, \psi_{\mathrm{C}}$ is become homogenous in the Y-type microchannel with obstacle as compared to Y-type microchannel without obstacle. The presence of the obstacle produced an addition momentum on the liquid-liquid interaction that enhanced the liquid-liquid (acetone-water) mixing. It can be concluding that supportive geometry on the microchannel such as the installation of an obstacle can be applied to enhance the mixing process as the mixing by molecular diffusion is quite sluggish.

\section{ACKNOWLEDGMENT}

The authors would like to thank Universiti Kebangsaan Malaysia for their financial support under the grant GUP2017-063.

\section{REFERENCES}

Ait Mouheb, N., Malsch, D., Montillet, A., Solliec, C. \& Henkel, T. 2012. Numerical and Experimental Investigations of Mixing in T-shaped and Cross-Shaped
Micromixers. Chemical Engineering Science 68(1): 278-289.

Almeida, R. A., Rezende, R. V. P., Cabral, V. F., Noriler, D., Meier, H. F., Cardozo-Filho, L. \& Cardoso, F. A. R. 2016. The effect of system temperature and pressure on the fluid-dynamic behavior of the supercritical antisolvent micronization process: a numerical approach. Brazilian Journal of Chemical Engineering 33(1): 73-90.

Bothe, D., Stemich, C. \& Warnecke, H. J. 2006. Fluid mixing in a T-shaped-mixer. Chem. Eng. Sci. 61: 2950-2958.

Engler, M., Kockmann, N., Kiefer, T. \& Woias, P. 2004. Numerical and experimental investigations on liquid mixing in static micromixers. Chemical Engineering Journal 101(1-3): 315-322.

Eswaran, V. \& Pope, S. B. 1988. Direct numerical simulation of the turbulence mixing of a passive scalar. The Physics of Fluids 31(3): 506-520.

Henrik, V. H. L. \& Wolfgang, E. 2000. Microreactors: New Technology for Modern Chemistry. John Wiley $\&$ Sons.

Iglberger, K. Thürey, N. \& Rüde, U. 2008 Simulation of moving particles in 3D with Lattice Boltzmann method. Computers and Mathematics with Applications 55(7): 1461-1468.

Jason, B. 2010. COMSOL Experimental Biophysics: Solid State Physic. Lund University.

Johnson, T. J., Ross, D. \& Locascio, L. E. 2002. Rapid microfluidic mixing. Analytical Chemistry 74(1): 4551.

Miložič, N., Lubej, M., Noval, U., Žnidaršič-Plazl, P. \& Plazl, I. 2014. Evaluation of diffusion coefficient determination using a microfluidic device. Chemical and Biochemical Engineering Quarterly 28(2): 215-223.

Othman, N. T. A., Obara, H. Choi, J.-E. \& Takei, M. 2012. Temporally transitional cross-sectional capacitance measurement of micro particle concentration in the microchannel. Japanese Journal of Multiphase Flow 25(5): 423-434.

Othman, N. T. A., Obara, H. \& Takei, M. 2013. Measurement of fine particles concentration in microchannel using capacitance measurement method. Japanese Journal of Multiphase Flow 27(2): 152-159.

Othman, N. T. A. \& Takei, M. 2015. Application of electrical capacitance tomography for dense cross-sectional particle migration in a microchannel. Jurnal Teknologi 77(17): 85-90.

Othman, N. T. A. \& Wahid, N. S. 2017. Measurement of gas holdup and mass transfer in a bubble column by using electrical resistance tomography (ERT). Jurnal Kejuruteraan 29(2): 113-119.

Othman, N. T. A., \& Farid, A. N. M. 2018. Droplets tracing in a T-junction microchannel. Jurnal Kejuruteraan 30(1): 47-53

Rudyak, V. \& Minakov, A. 2014. Modelling and optimization of Y-Type micromixers. Micromachines 5(4): 888-912.

Soleymani, A., Kolehmainen, E., Turunen, I. 2008. Numerical and experimental investigations of liquid mixing in $\mathrm{T}$ - 
type micromixers. Chemical Engineering Journal 135: 219-228.

Wang, H., Iovenitti, P., Harvey, E., Masood, S. \& Rowan. 2002. Optimizing layout of obstacles for enhanced mixing in microchannels. Smart Mater Struct 11: 662667.

Wong, S., Ward, M. \& Wharton, C. 2004. Micro T-mixer as a rapid mixing micromixer. Sensors and Actuators B: Chemical 100(3): 359-379.

*Nur Tantiyani Ali Othman

Research Centre for Sustainable Process Technology (CESPRO)

Chemical Engineering Programme,

Faculty of Engineering and Built Environment,

Universiti Kebangsaan Malaysia, Selangor, Malaysia

Ahmad Amri Anis

Chemical Engineering Programme,

Faculty of Engineering and Built Environment,

Universiti Kebangsaan Malaysia, Selangor, Malaysia

*Corresponding author; email: tantiyani@ukm.edu.my

Received date: $3^{\text {rd }}$ April 2018

Accepted date: $18^{\text {th }}$ May 2018

Online First date: $1^{\text {st }}$ October 2018

Published date: $30^{\text {th }}$ November 2018 